\title{
INNOVATIVE TECHNIQUES FOR THE DESCRIPTION OF RESERVOIR HETEROGENEITY USING TRACERS
} \author{
January-March 1991 \\ By \\ Gary Pope \\ Kamy Sepehrnoori
}

Quarterly Report for the Period

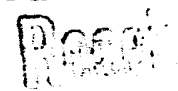

September 1991

Work Performed Under Contract No. DE-AC22-90BC14653

\author{
Edith Allison, Project Manager \\ Bartlesville Project office \\ P. O. Box 1398 \\ Bartlesville, OK 74005
}

\author{
Prepared by \\ The University of Texas \\ Department of Petroleum Engineering \\ Austin, TX 78712
}

\section{DISCLAIMER}

\begin{abstract}
This report was prepared as an account of work sponsored by an agency of the United States Government. Neither the United States Government nor any agency thereof, nor any of their employees, makes any warranty, express or implied, or assumes any legal liability or responsibility for the accuracy, completeness, or usefulness of any information, apparatus, product, or process disclosed, or represents that its use would not infringe privately owned rights. Reference herein to any specific commercial prodict, process, or service by trade name, trademark, manufacturer, or otherwise does not necessarily constitute or imply its endorsement, recommendation, or favoring by the United States Government or any agency thereof. The views and opinions of authors expressed herein do not necessarily state or reflect those of the United States Government or any agency thereof.
\end{abstract}




\section{OBJECTIVES}

The objective of this research is to develop an advanced, innovative technique for the description of reservoir heterogeneity. This proposed method consists of using tracers in singlewell backflow tests. The general idea is to make use of fluid drift in the reservoir either due to naturally occurring pressure gradients in the reservoir, or by deliberately imposed pressure gradients using adjacent injection and production wells in the same reservoir. The analytical tool that will be used to design and interpret these tests is a compositional reservoir simulator with special features added and tested specifically for this purpose.

\section{INTRODUCTION}

A tracer option has been implemented in our compositional simulator to study gas tracers used in miscible floods. It can l andle nonpartitioning water, oil, and gas tracers. The first feature added to the new tracer option is radioactive decay. We show some of the test runs using this new option in this report. Other features, testing, and applications are in progress.

\section{SUMMARY OF TECHNICAL PROGRESS}

\section{Implementing Tracer Option in UTCOMP}

UTCOMP is an equation-of-state, compositional, 3D reservoir simulator initially developed by Chang et al. (1990). It has the usual features of most industrial compositional simulators plus special numerical and physical options useful for research on enhanced oil recovery. The following assumptions were made for this initial effort to implement a tracer option:

1. no adsorption

2. no partitioning

3. no chemical reaction

4. tracers do not change physical properties of fluids or the phase behavior.

From the above assumptions, the mass conservation equations describing gas, oil, or water tracers in porous media can be written as

$$
\frac{\partial\left(\phi \rho_{\ell} \omega_{l, \ell} S_{\ell}\right)}{\partial t}+\vec{\nabla} \cdot \rho_{\ell} \omega_{i, \ell} \vec{u}_{\ell}-\vec{\nabla} \cdot \phi \rho_{\ell} S_{\ell} \overrightarrow{\vec{K}}_{i, \ell} \cdot \nabla \omega_{i, \ell}-q_{i}=0
$$

The decay rate for radioactive tracer $i$ is

$$
\frac{\mathrm{dN}}{\mathrm{dt}}=-\lambda_{\mathrm{i}} \mathrm{N}_{\mathrm{i}}
$$

where

$$
N_{i}=V_{b} \phi \rho_{\ell} \omega_{i, \ell} S_{\ell}
$$


and

$$
\lambda_{i}=\frac{\ln (0.5)}{\left(!_{1 / 2}\right)} .
$$

In finite-difference form, Eq. 2 becomes

$$
N_{i}^{n+1}=N_{i}^{n}\left(1-\lambda_{i} \Delta t\right) \text {. }
$$

The steps to compute the material balance for tracers are as follow:

1. Solve the pressure equation for nontracer components

2. solve the mass conservation equations for nontracer components

3. compute the phase compositions for nontracer components

4. compute phase densities, saturations, relative permeabilities, capillary pressures for nontracer components

5. solve the mass conservation equations for tracer components

6. if radioactive tracer is used, use Eq. 3 to calculate amount of tracers remaining at the end of timestep

7. return to step 1 for the next timestep

Although two material balance components with identical properties, but with different initial and injected concentrations, can be used to simulate a tracer, and this may be necessary in some cases, the above proredure saves large amounts of computer time.

\section{Test Runs Using Tracer Option}

Figure 1 shows an example comparison between the analytical solution and the numerical solution for the $1 \mathrm{D}$ convection-diffusion equation at a Peclet number of 200.

To test the decay feature, a nondecaying water tracer and a decaying tracer with $\lambda_{i}$ of 0.0087 (1/day) were injected as $10 \%$ total pore volumes slugs. The run was carried out to 120 days (1.5 PVI). The mean residence time for the nondecaying tracer was about 80 days, which was equal to the decaying tracer's half-life. Figure 2 shows the results. The peak concentration for the nondecaying tracer is about 0.37 , while the peak concentration for the decaying tracer is about 0.185 .

Figure 3 shows a comparison between the 2D analytical solution for single-phase tracer flow in a homogeneous five-spot well pattern (Abbaszadeh-Dehghani and Brigham, 1983) and the numerical solution using a $30 \times 30$ grid. The agreement is good.

The next test run is a 1D water flood with a water tracer. Figure 4 shows saturation and tracer concentration profiles at 0.2 pore volumes injected. As predicted from fractional flow theory, the tracer concentration front lags behind the water saturation front.

We also show an example simulation of a gas tracer in a $\mathrm{CO}_{2}$ flood. A gas tracer with the same properties as $\mathrm{CO}_{2}$ was injected to displace stock tank oil at 1000 psia and $126.5^{\circ} \mathrm{F}$. The $\mathrm{CO}_{2}$ tracer slug size was $10 \%$ of the total pore volume and the tracer concentration was $1 \%$. For comparison, we also made a tracer simulation for a singlephase, first-contact miscible displacement with the same slug size and tracer concentration. The permeability field in this example was generated using a stochastic model with a 
heterogeneity index $0_{i} 2.97$. The heterogeneity index is defined as $\sigma^{2} \lambda_{\mathrm{DX}}$. The results are shown in Fig. 5.

\section{NOMENCLATURE}

$\begin{array}{rll}\overline{\bar{K}} & = & \text { dispersion tensor }\left(\mathrm{ft}^{2} / \text { day) }\right. \\ \mathrm{N}_{\mathrm{i}} & = & \text { total mass of tracer } \mathrm{i}(\mathrm{lbm}) \\ \mathrm{q}_{\mathrm{i}} & = & \text { mass flow rate of tracer } \mathrm{i}(\mathrm{lbm} / \text { day) } \\ \mathrm{S}_{\ell} & = & \text { phase saturation (fraction) } \\ \mathrm{t} & = & \text { time (days) } \\ \mathrm{t}_{1 / 2} & = & \text { half-life (days) } \\ \overrightarrow{\mathbf{u}}_{\ell} & = & \text { total flux of phase } \ell(\mathrm{ft} / \text { day) } \\ \mathrm{V}_{\mathrm{DP}} & = & \text { Dykstra-Parson coefficient } \\ \nabla & = & \text { gradient operator }\end{array}$

\section{Greek symbols}

$\begin{array}{rll}\lambda_{\mathrm{DX}} & = & \text { dimensionless correlation length } \\ \lambda_{\mathrm{i}} & = & \text { rate of decay (1/day) } \\ \sigma^{2} & = & \text { variance of permeability distribution } \\ \rho_{l} & =\text { mass density of phase } \ell\left(\mathrm{lbm} / \mathrm{ft}^{3}\right) \\ \phi & =\text { porosity (fraction) } \\ \omega_{\mathrm{i}, \ell} & =\text { concentration of tracer } \mathrm{i} \text { in phase } \ell \text { (mass fraction) }\end{array}$

\section{Subscripts}

$\begin{array}{lll}\ell & = & \text { phase index }(o, w, g) \\ i & = & \text { component index }\end{array}$

\section{REFERENCES}

Abbaszadeh-Dehghani, M. and Brigham, W.E.: "Analysis of Unit Mobility Ratio Well-toWell Tracer Flow to Determine Reservoir Heterogeneity," U.S. DOE Report SF/11564-1, Feb. 1983, SUPRI TR-36.

Chang, Y., Pope, G.A., and Sepehmoori, K.: "A Higher-Order Finite Difference Compositional Simulator,” J. Pet. Sci. Eng. (1990) 5, 35-50. 


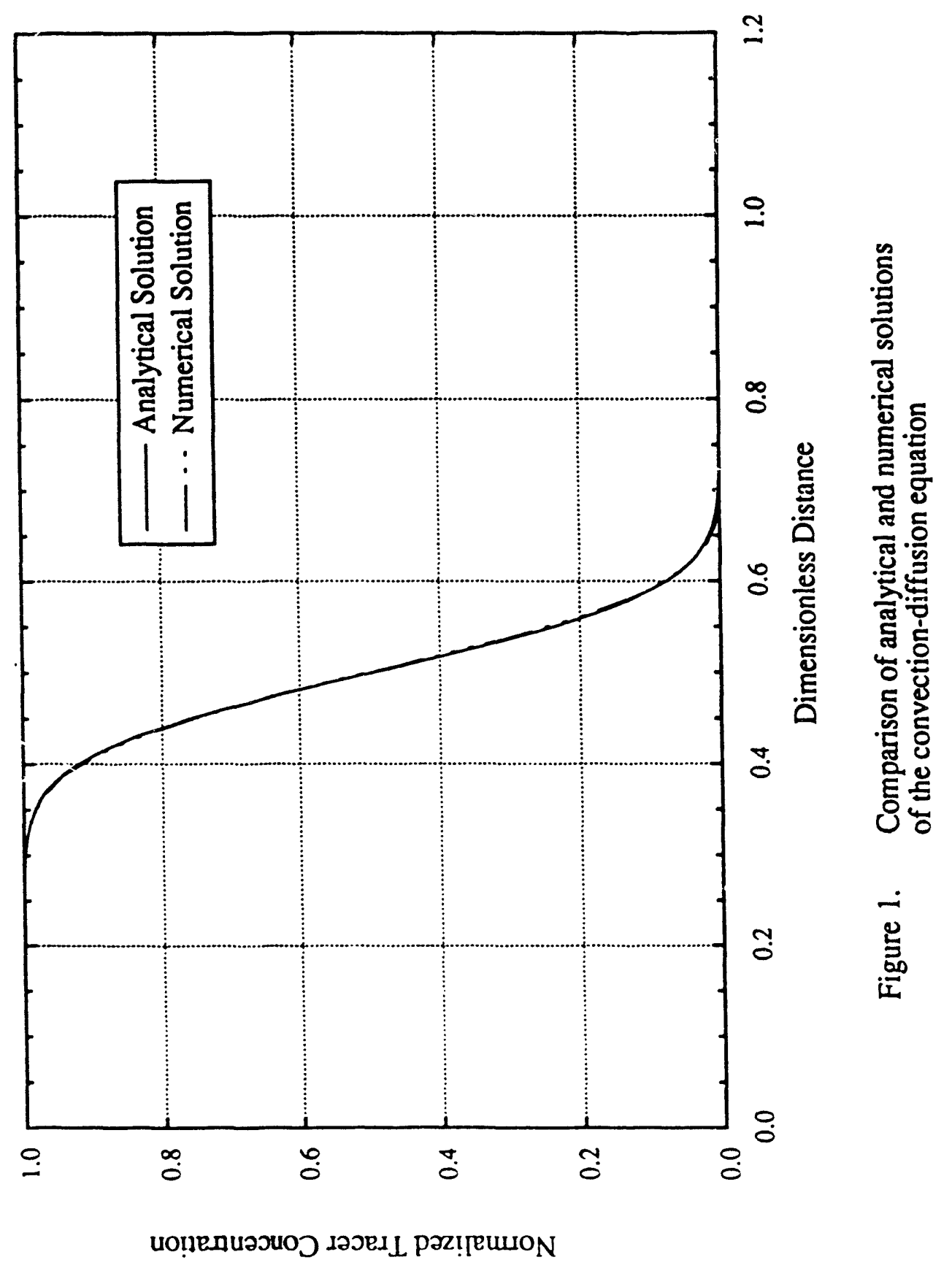




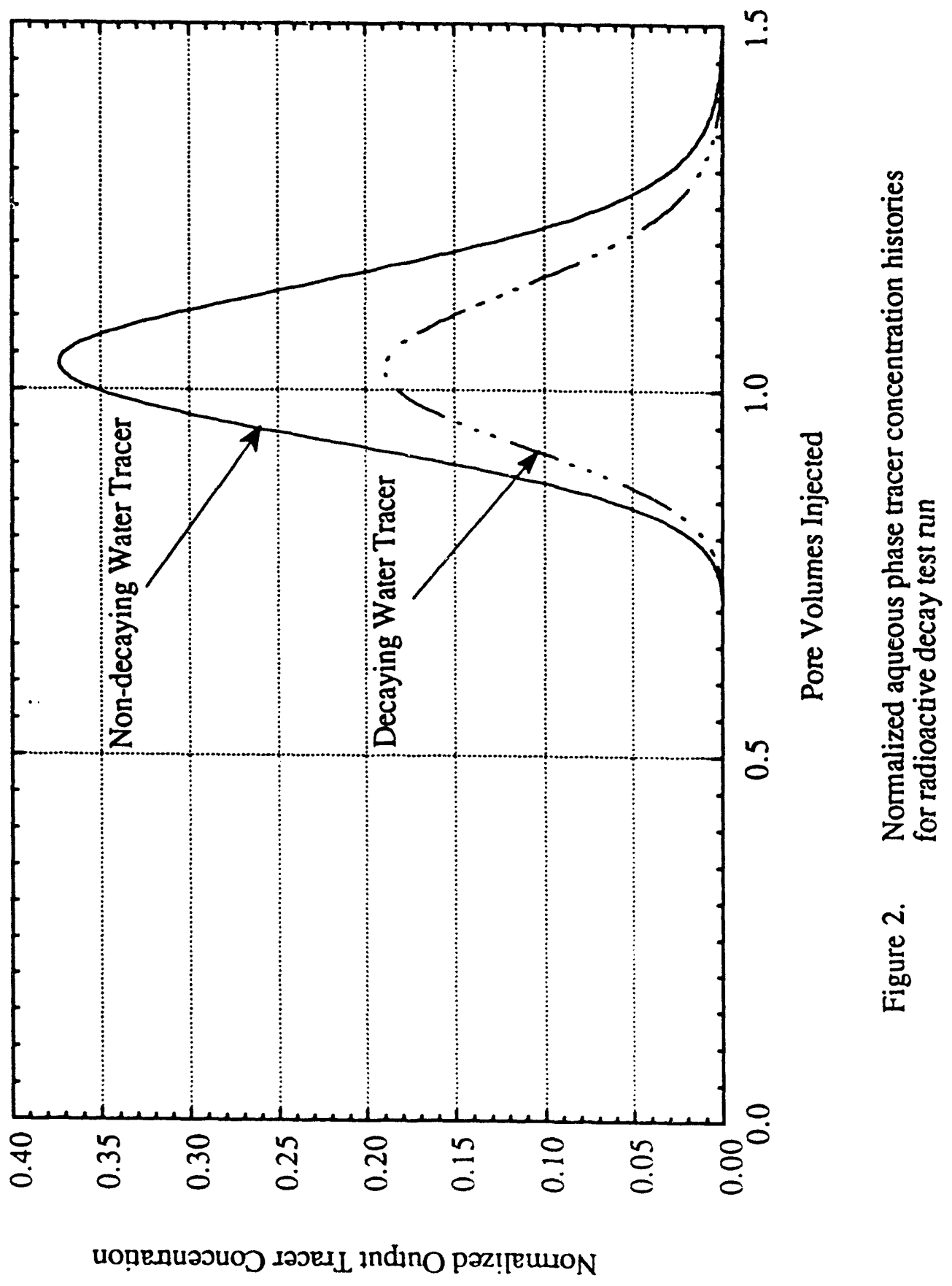




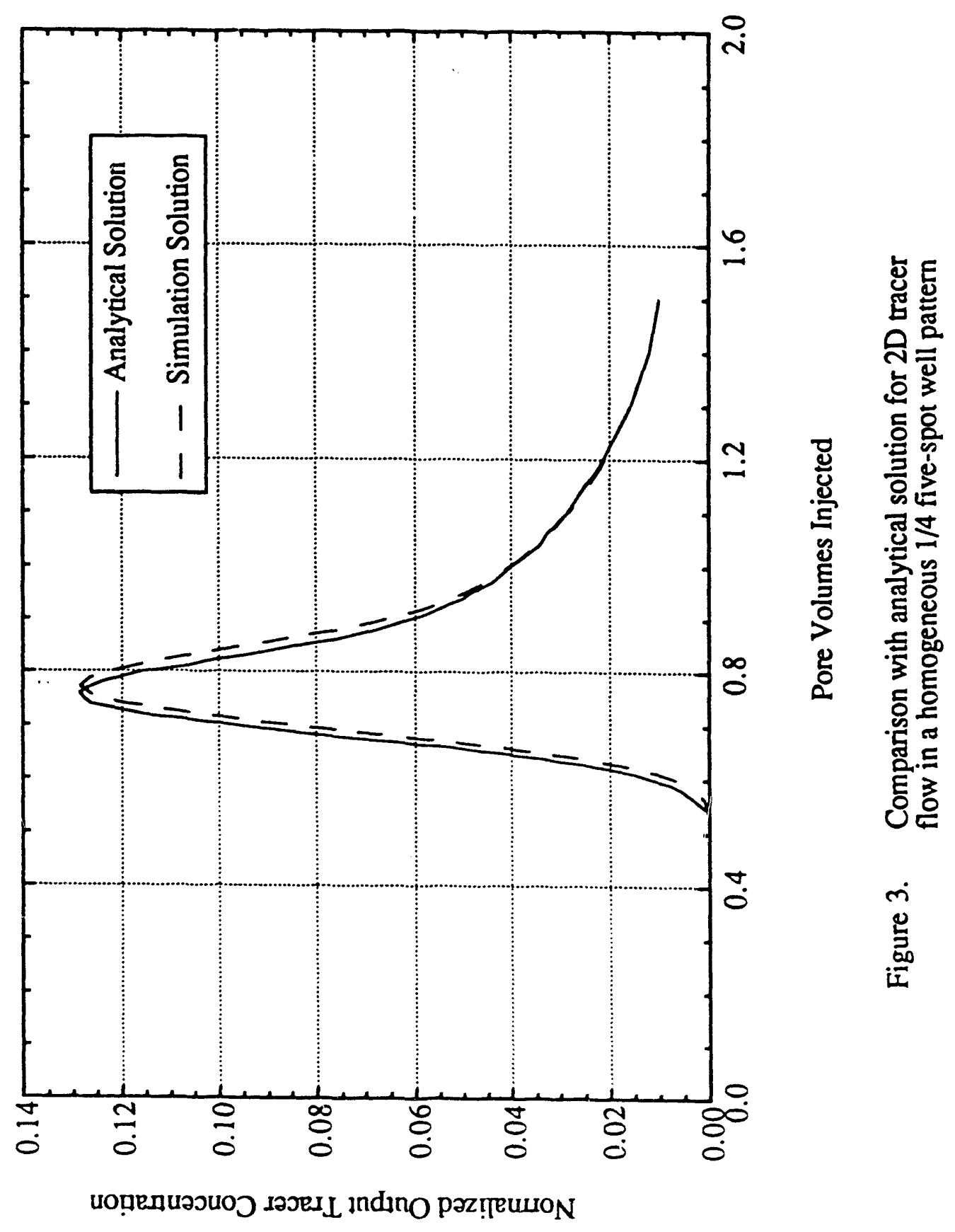




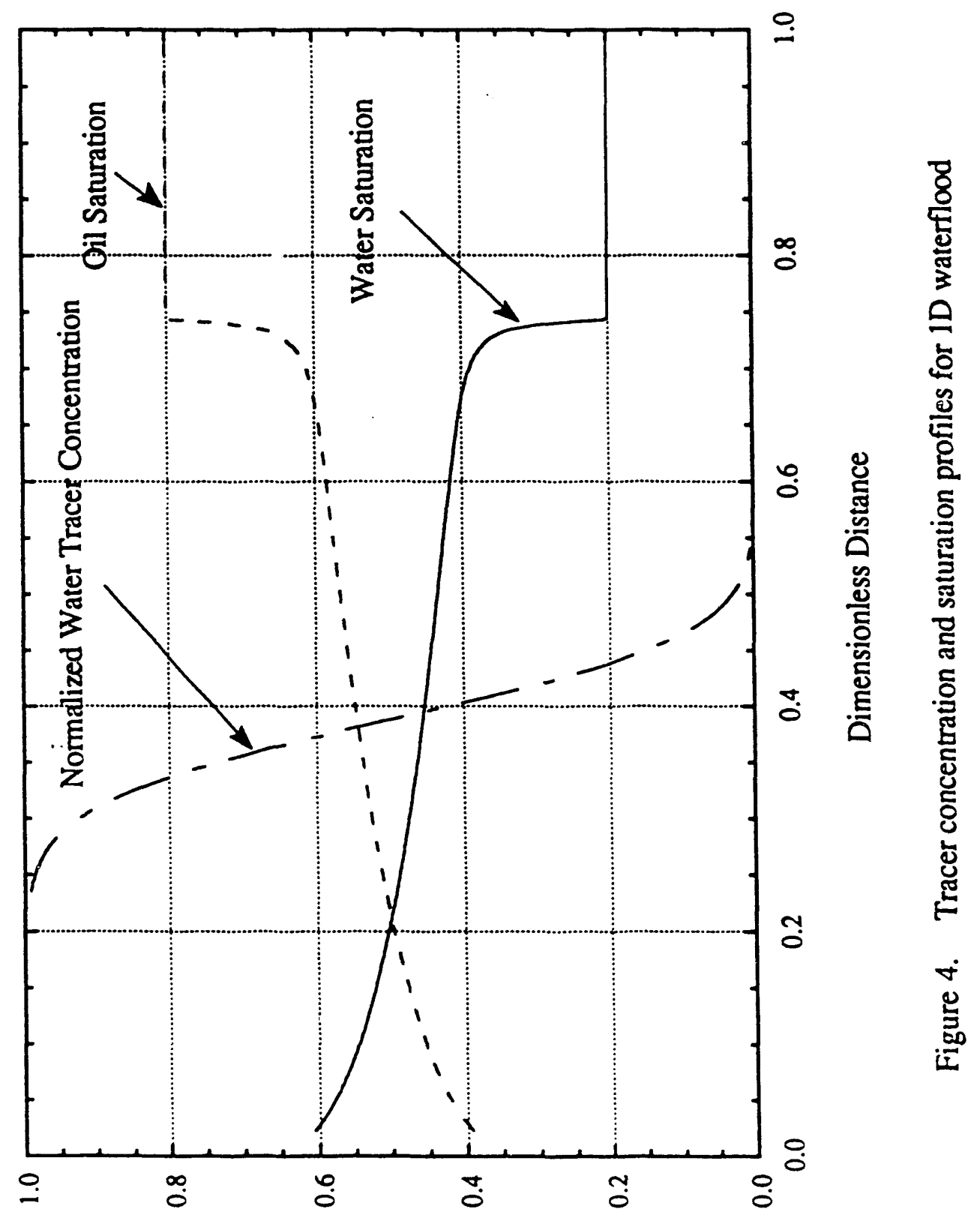

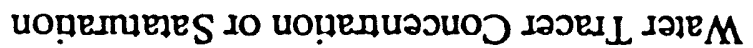




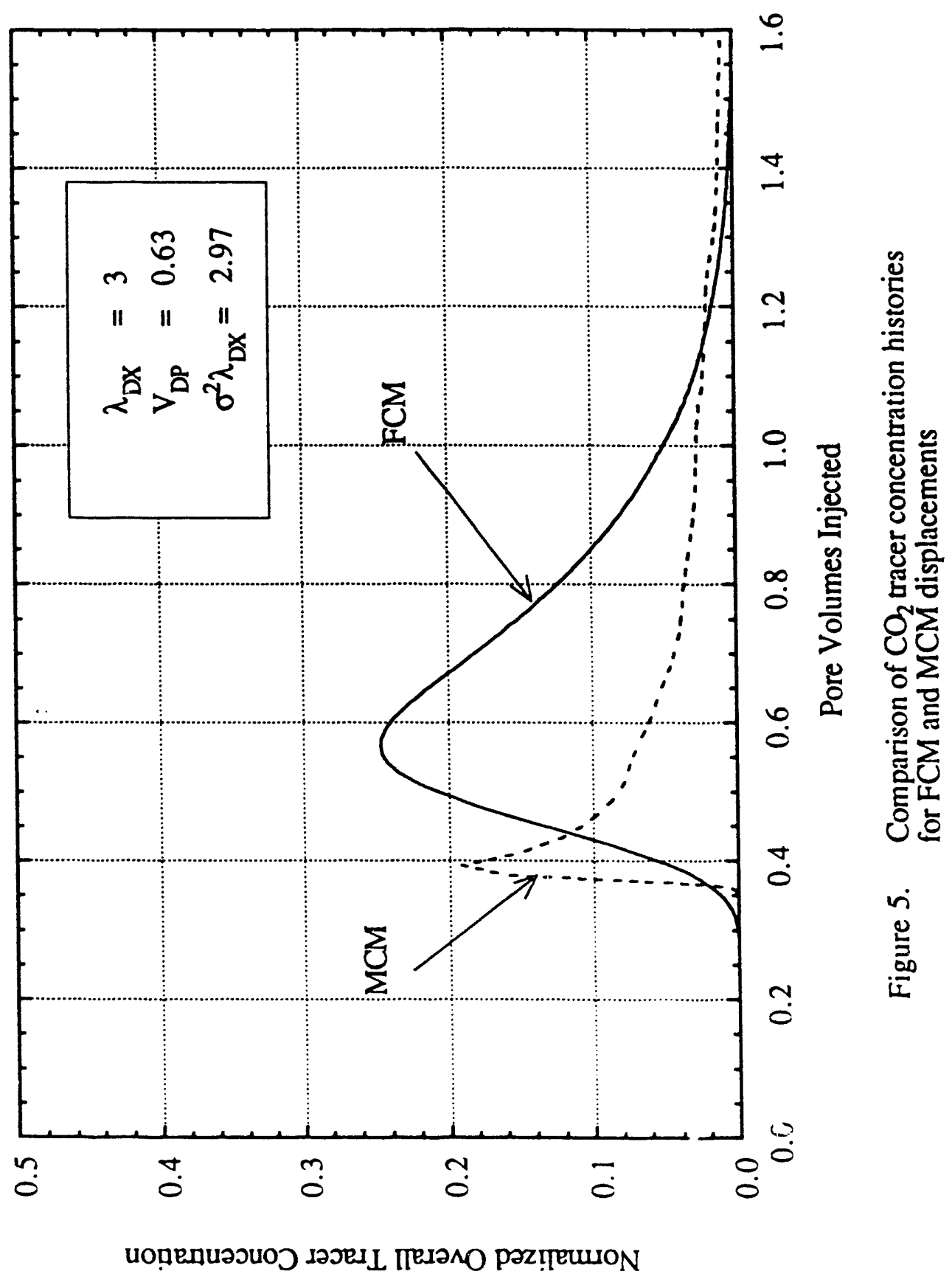



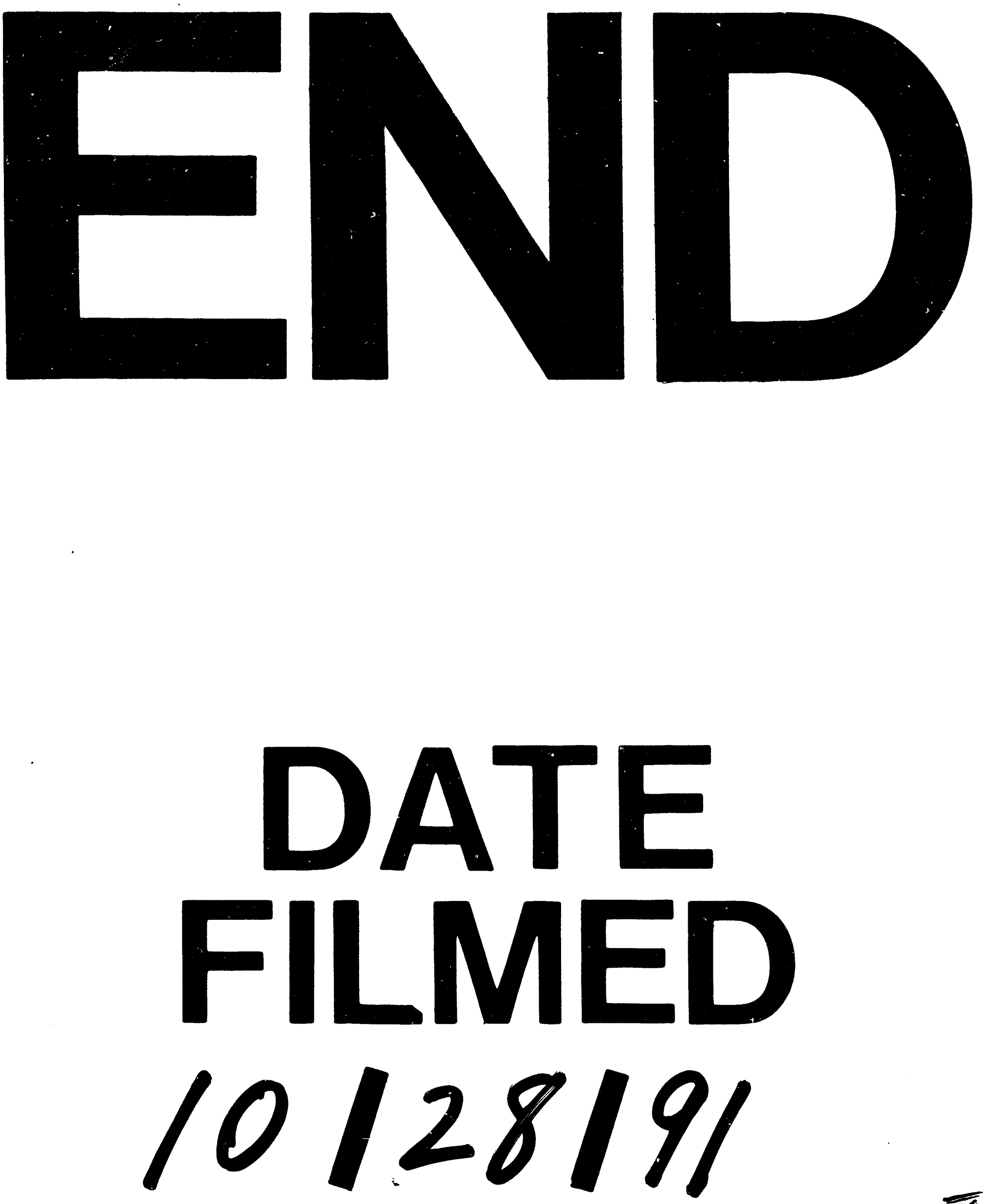
